\title{
Determine Personality Traits-Tasks-Vocational Rehabilitation for the Sport Psychologist in the Egyptian Society "Practical Analytical Study"
}

\author{
Wafaa Darwish*
}

\begin{abstract}
The research aims to specify personality manners - duties - vocational rehabilitation for sport psychologist (practical, analytical study) which can be used as a standard to choose what can be fit in order to occupy this job. The researcher used the descriptive method, and she designed a questionnaire to specify duties. The researcher recommends with the necessity of making use of the specifications, which she had reached through this as an indicator for choosing the sport psychologist according to standard which can be used in the sport field.
\end{abstract}

\section{Introduction and the problem of research}

$\mathrm{T}$ he process of coaching contribute to the achievement of balance between the requirements of sporting activity and capabilities of the individual practitioner and preparations to reach the highest levels and achieve victory, reaching the level of achievement does not come only through systematic training for a long time for the preparation of an integrated physical and ambulant and intellectually and psychologically.

There is no doubt that a comprehensive educational training process as a multifaceted training program is a series of seminars, procedures and services, and if one of them lost weakened chain

And the nature of methods used to develop faith and personality traits associated with sports training and affecting more clear on the level of the individual sports, they did not receive sufficient attention from instructors only recently been in recent years have seen growing interest in the field of application of the psychology of sport and become familiar with the psychological skills training to develop skills Kinetic and physical abilities and respects the plans.

* Professor of Sports Psychology, Department of Educational Sciences, Psychological and Social, College of Physical Education for Girls, Alexandria University, Egypt.
Since the preparation and physical skills and plans a shared responsibility between the sports coach and fitness coach and the outline of the training loads so psychological preparation and the process of acquiring skills and education of the players responsible for the psychological need of attention.

He has Ka of rateb (1995), Allawi (1997) that the psychological specialist sports is the person who shall teach players skills and giving psychological and service applications to improve performance

The Olympic Committee has taken the United States of America in 1983 to identify persons entitled to practicing the profession of specialist sports in the area of psychological clinical work - $\mathrm{R}$ - extension

Rateb (1995), Annan (1995), Allawi (1998)

It is evident here is the labor market need for a psychological specialist with the sports Ariyadeyen so that access to the best levels in professional sports.

The importance of the problem in the absence of a psychological specialist sports personality in the Egyptian society, despite the important role to play in teaching and directing and guiding the players and create a mental state to achieve victory and success, which prompted the researcher to study this phenomenon to develop a model of psychological specialist sports. 


\section{The goal of research}

Touching personal identification - tasks vocational rehabilitation for the sport psychologist (Practical analytical study), which can be used as criteria for the selection of psychologists in sports.

\section{Research questions}

1. Is there a qualified psychologist to work with players in sports teams?

2. What personal characteristics that must be met by specialist mental sports?

3. What are the main tasks carried out by specialist mental sports?

4. How can the psychological rehabilitation specialist sports?

\section{Research prouder}

\section{First: methodology}

Researcher used descriptive approach.

\section{Second: The sample research}

The study was conducted on a sample of qualified trainers and athletes have experience in training activities of the individual, Alexandria governorate, where numbered (20) as coach of trainers: (Fencing - swimming taekwondo - basketball.

\section{Third: research tools}

A - The researcher design form an opinion poll of scholars from Drew prep sports specialist mental faculties established sports Egypt from 2004 / 2005 / 2006 to identify the personal and psychological nature of specialist sports.

(First survey) facility (1)

B - Designed to form an opinion poll trained athletes qualified for some sports teams to determine the nature and functions of specialist mental sports that found in Egyptian society. (Second survey) facility (2)

\section{Statistical method}

Percentages used in the form of a chart.

\section{Show Results}

Table (1)

Clarify the answers that determine personality traits of the psychological specialist sports

\begin{tabular}{|c|c|c|c|}
\hline M & Responses & $\begin{array}{c}\text { N= } \\
20\end{array}$ & $\begin{array}{c}\text { The relative } \\
\text { importance }\end{array}$ \\
\hline 1 & That is characterized by smiles and social creatures and will. & 20 & 1 \\
\hline 2 & Enjoy the appropriate degree of intelligence and self-confidence. & 17 & 2 \\
\hline 3 & Be the subject of trust and respect of the players. & 16 & 3 \\
\hline 4 & Only the personal and has the ability to the art of leadership. & 15 & 4 \\
\hline 5 & Has the ability to make wise decisions. & 14 & 6 \\
\hline 6 & That respects the ethical standards of the profession and the satisfaction of his & 14 & 6 \\
\hline 7 & whark in charge of it. & 14 & 6 \\
\hline 8 & Har chacterized by honesty and truthfulness in words and action. & 13 & 8 \\
\hline 9 & Marked by emotional balance, patience and calm. & 12 & 9 \\
\hline 10 & That respects the theory of integrated unit rights. & 12 & 10 \\
\hline 11 & & 10 & 1 \\
\hline
\end{tabular}


Table (2)

Clarify the answers that define the functions of psychological specialist sports

\begin{tabular}{|c|c|c|c|}
\hline M & Responses & $\begin{array}{c}\mathrm{N}= \\
20\end{array}$ & $\begin{array}{l}\text { The relative } \\
\text { importance }\end{array}$ \\
\hline 1 & Create the players psychologically before participating in sports competitions & 20 & 1 \\
\hline 2 & Providing educational concepts scientifically valid. & 17 & 2.5 \\
\hline 3 & To mobilize the energy of the players on the psychological sources Tariff positive. & 17 & 2.5 \\
\hline 4 & To modify the behavior of the players and coach and the public. & 16 & 4.5 \\
\hline 5 & $\begin{array}{l}\text { To assist players in the psychological skills to upgrade and develop the sports level } \\
\text { away from the psychological pressure. }\end{array}$ & 16 & 4.5 \\
\hline 6 & Is able to access the degree of super players alike. & 15 & 6.5 \\
\hline 7 & $\begin{array}{l}\text { Is professionally trained to assist the sports player to gain psychological support in the } \\
\text { face difficult conditions in the competition and training. }\end{array}$ & 15 & 6.5 \\
\hline 8 & $\begin{array}{l}\text { Serve as a Thermometry athlete and a link between each of dealing with the sport (the } \\
\text { technical staff - administrative). }\end{array}$ & 13 & 9 \\
\hline 9 & Has the capacity to achieve growth of psychological thing. & 13 & 9 \\
\hline 10 & Have the scientific expertise in both areas of Asuiae and those in need (disabled). & 13 & 9 \\
\hline 11 & $\begin{array}{l}\text { To be qualified scientifically and educationally, psychologically and has a background } \\
\text { in the field of expanding sports psychology. }\end{array}$ & 11 & 12 \\
\hline 12 & $\begin{array}{l}\text { Had previous experience in the application of psychological and behavioral tests } \\
\text { occurring in the sport. }\end{array}$ & 12 & 10 \\
\hline 13 & has the ability to organize and exploitation of human energies optimally & 13 & 9 \\
\hline 14 & $\begin{array}{l}\text { Directing the players to solve some of the psychological and behavioral problems that } \\
\text { occur in sports. }\end{array}$ & 14 & 8 \\
\hline 15 & $\begin{array}{l}\text { has a role in guiding the aggressive behaviors as well as dealing with the concerns of } \\
\text { competition for players }\end{array}$ & 15 & 7 \\
\hline 16 & Contribute to maintaining mental health of players. & 16 & 6 \\
\hline 17 & Has a role in the process of rehabilitating the injured player was injured sport. & 17 & 5 \\
\hline
\end{tabular}

Table (3)

Clarifies that determine the answers to vocational rehabilitation specialist psychological Sports

\begin{tabular}{|c|c|c|c|}
\hline M & Responses & $\begin{array}{c}\mathrm{N}= \\
20\end{array}$ & $\begin{array}{l}\text { The relative } \\
\text { importance }\end{array}$ \\
\hline 1 & $\begin{array}{l}\text { Polishing special training courses on how to apply theories of self-sports for all the } \\
\text { different sectors. }\end{array}$ & 20 & 1.5 \\
\hline 2 & $\begin{array}{l}\text { Was established to guide the care of the psychological growth of educational } \\
\text { institutions in various stages Sunni. }\end{array}$ & 20 & 1.5 \\
\hline 3 & $\begin{array}{l}\text { the improvement and development of thought among the players by providing the } \\
\text { correct information for each sport }\end{array}$ & 17 & 3.5 \\
\hline 4 & Providing job opportunities in therapeutic institutions (delinquents - addicts). & 17 & 3.5 \\
\hline 5 & $\begin{array}{l}\text { The rehabilitation of physical education graduates from colleges and refine enough } \\
\text { studies to reach the required level. }\end{array}$ & 16 & 5 \\
\hline 6 & The use of psychological specialist sports in the design of sports programmers. & 15 & 6.5 \\
\hline 7 & To provide special care for the elderly and those with special needs. & 15 & 6.5 \\
\hline 8 & $\begin{array}{l}\text { To begin to convince the community the need for quality and effective role for each } \\
\text { of the works. }\end{array}$ & 13 & 8 \\
\hline 9 & $\begin{array}{l}\text { Applied providing services for the education of sound psychological principles in } \\
\text { order to enhance the performance of practitioners. }\end{array}$ & 12 & 9 \\
\hline 10 & $\begin{array}{l}\text { Its contribution to the detection of talent and predict the appropriate level to assist in } \\
\text { the selection of good players. }\end{array}$ & 10 & 10 \\
\hline 11 & $\begin{array}{l}\text { Strengthening the physical aspects of preparations and plans for the player and } \\
\text { psychological allowing upgrading sports. }\end{array}$ & 8 & 11 \\
\hline 12 & $\begin{array}{l}\text { Benefit from the development of administrative and personal characteristics of the } \\
\text { athlete to reach high levels in the championship. }\end{array}$ & 5 & 12 \\
\hline
\end{tabular}


Table (4)

a proposal to clarify the model selection specialist psychological determinants of sports according to expert opinions

\begin{tabular}{|c|c|c|c|}
\hline \multirow{2}{*}{ Arrangement } & Tasks that determine the post of specialist psychological & $\begin{array}{c}\text { Average } \\
\text { grades }\end{array}$ & $\begin{array}{c}\text { The distribution of } \\
\text { grades }\end{array}$ \\
\cline { 3 - 4 } & & 240 & 48 \\
\hline 1 & Vocational rehabilitation specialist for psychological & 180 & 36 \\
\hline 2 & Personality traits that determine the psychological \\
specialist & 80 & 16 \\
\hline 3 & Total degrees (5) experts & 500 & 100 Degree \\
\hline
\end{tabular}

Determine the degree of choice of specialist sports psychological than 100 degrees are distributed as shown in table (4) If the individual is located 75 degrees and more choice for the post.

\section{Clarifies that determinetraits of psychological specialiste Sports}

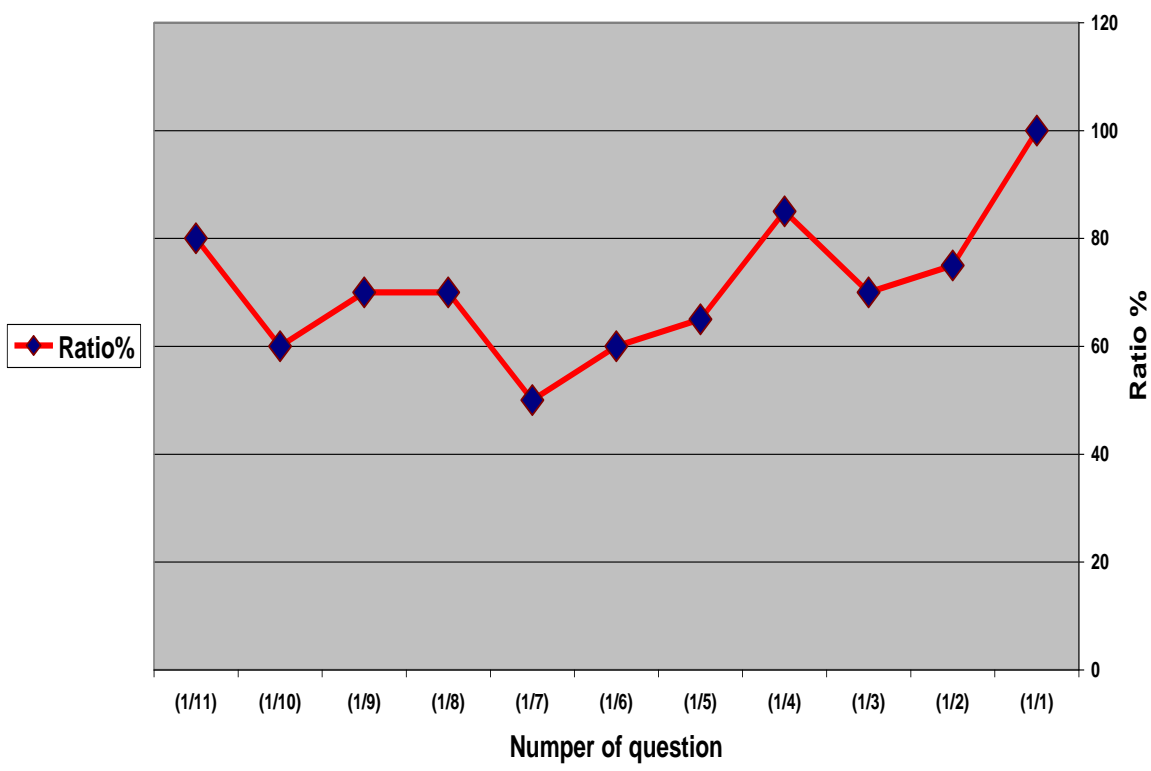

clarifies that define the Faunctions of Psychdogicol Specialist Sports

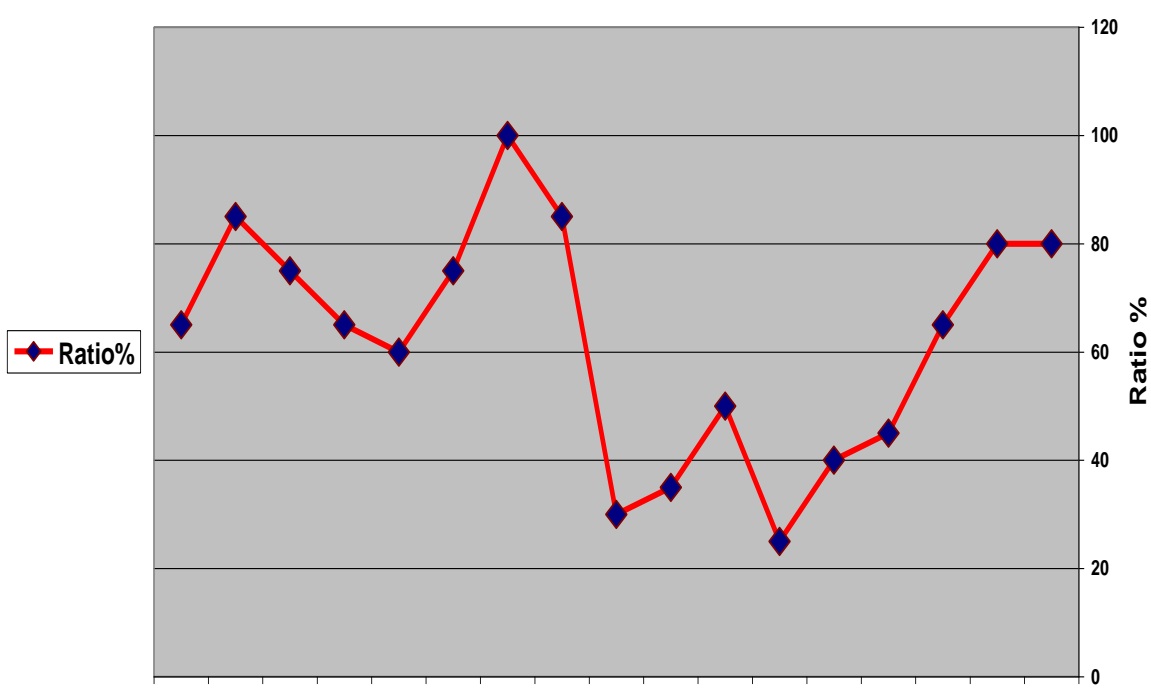

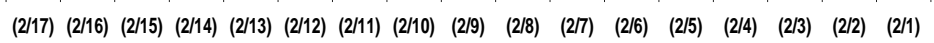

Numper of question 


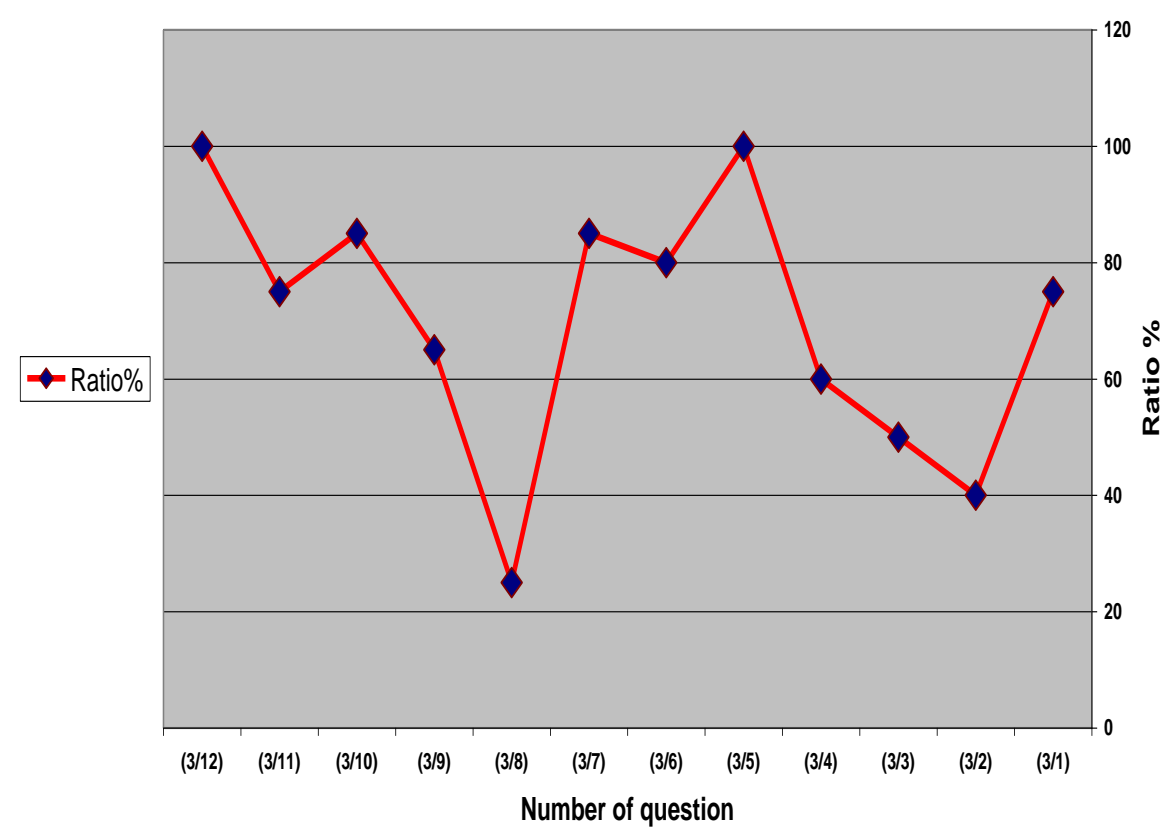

\section{Discuss the findings}

Table (1) to determine the relative importance of searching for answers sample characteristics that define personal psychological specialist sports descending order, according to the views of specific shows that figure (1) Graphic\% ratio to determine which range between $100 \%$ graduated up to $50 \%$ as it emerged a convergence of arranging personal characteristics that should be available in specialist sports psychological necessary degree of intelligence and self-confidence, honesty and truthfulness and emotional equilibrium and ethical standards that govern the nature of his profession and respect for rights deals In addition to his happiness and welfare of individuals who deal with them and his personality can be balanced and in control of emotions. Rateb (1997), Allawi (1998), Bxia (1997), Ruch (1997).

The table (2) to determine the relative importance of searching for answers sample tasks psychological specialist sports Tnzlea order, in accordance with the views of specific shows that figure (2) chart to determine\% which ranged from $100 \%$ to $25 \%$ as tasks are arranged according to their importance as The presence of psychological specialist with the sports team sports is one of the important things that help in psychological rehabilitation for the player before participating in sports competitions with the provision of comprehensive care and ease the psychological pressure that is one of the main causes combustion with the use of the sports best means to achieve treatment and rest and relaxation as well as developing the skills of communication between Coach and player, Annan (1995), Allawi (1997), Miud (1998 ), Cox (1994) .

The researcher sees the need for a specialist psychological and educationally qualified scientifically and mathematically with sports teams as the future vision emphasizes the importance of the availability of more than a psychologist in the same team, one of whom regard the process of selecting players, the other team cohesiveness and the third to increase the driving players to ensure the success of the training process and achieve better access to Levels of sports.

There is no doubt that efficient worker has the capacity to analyses the performance by the player with the follow-up to the emergency circumstances that faced with the provision of expertise and information required for the correct position Altai sports David (1995),Lippman (1997), Ruch (1997). 
The Table (3) to determine the relative importance of searching for answers to a sample of vocational rehabilitation specialist psychological descending order, in accordance with the views outlined shows the form (3) to chart the challenge $\%$ ratio ranging from $100 \%$ to $25 \%$ as it was arranged rehabilitation methods that contribute to Psychological assistance specialist for the effective role within the sports teams, in terms of refined special training courses on how to apply the theories of self-sports players and develop thinking and ability to draw notice was established to achieve growth and development of psychological thought the players and his ability to how to deal with every player in accordance with the programmer includes psychological preparation and also identified The modern training methods that are in harmony with the nature of sport be exercised by the player has the ability to transform the position of failure to successfully position with psychosocial support for the player in the face of difficult circumstances through training Dudejoanl (1996),Brian Meal (1998), Sport Science (1998)

Through the discussion of previous results were accessible to answer questions on the research identified by the researcher.

\section{Deductions}

\section{Could be reached through the discussion of the results}

1. To identify some personal traits that must be available in specialist mental sport.

2. Challenging tasks of psychological specialist sports that qualify for the job entrusted to it.

3. Identification of vocational rehabilitation contributing to the success of the work of worker the same parameters as commensurate with the selection of this post.

\section{Recommendations}

\section{Researcher recommends the following}

1. The necessity of expanding training programmers to participants in addition to the privileged elite players and trainers participate in training programs and methods of psychological skills training in preparation for his involvement with the psychological specialist in the application of mathematical concepts and theories of psychological training methods.

2. Must include formations of functional teams of specialist psychological due to its effective role in the follow-up psychological preparation as well as the policy-making short-and longterm preparation of the same skills as the socalled "Music of the so-called psychological profiling or psychological preparation for personal study and increase player Daffiest and directing for optimum performance.

3. Use Determinants reached by the researcher, through this study in the selection of specialist sports psychological according to the criteria is used in the sport.

\section{References}

1. Allawi Hassan Mohammad: self-coach and physical training, knowledge management, Cairo, 1997 p. 121: 127.

2. — : psychology of professional player and coach sports, book publishing center, Cairo 1998, p. 25: 27.

3. - the entrance in sports psychology, Dar Arab Thought, Cairo 1998, p. 5: 6.

4. sports psychology, Dar Arab Thought, Cairo, 1998.

5. Annan Abdel-Fattah Mahmoud: psychology of Physical Education and Sports, Dar Arab Thought, Cairo, 1995 p. 19: 20.

6. Brian Meal: Sport couch psychology why do we need psychology in sports in internet 1998.

7. Bxia Wac: sport couch - relazation programmed. U. R; Axihytm December Vol 40 No.3 1997.

8. Cox.R: sport psychology, Concepts and applications john wily \& sond find land in internet 1994. 
9. David G: Psycho Physiology and sport performance Ind ... Stuart (Ed) funopeah perspective on exercise and sport psychology human kinetics publishers in internet 1995.

10. Dudo Joonl: Maximizing motivation in sport and physical education among and adolescents. Journal Article V 48 No 31996.

11. Lippmann L. G: the role of imagexy in physical performance, international Journal for psychology 1997.

12. Martian: Seligman, ph D and George buchonon ph D learned optimism yields heralds benefits in internet 1998 .

13. Mind Plus Muscle, con mental training room, institute for app bed sport psychology 1998.
14. Rateb Kamel Osaman: The Psychology of Sport, Dar Arab Thought, Cairo 1995, p 27: 38.

15. psychological preparation for the training of young people, guide trainers and parents, Dar Al 1997 Arab thought 199: 237.

16. Rush, B. S Lippman L. G. the role of imagery in physical performance international journal for sport psychology in internet 1997.

17. Shamon Araby Mohammad: psychological preparation for the training of young people, guide trainers and parents, Dar Arab Thought 1997, 199: 237.

18. Sports science: sport psychology sports commission. Http: www.auspertviau/ais/ais/bakt7 Html 1998. 